\title{
Mullerian adenosarcoma of the cervix: case report
}

\author{
Akinfenwa T. Atanda ${ }^{1,3 *}$, Osondu C. Agu ${ }^{2}$, Abubakar K. Modu ${ }^{3}$ \\ ${ }^{1}$ Department of Pathology, Bayero University/Aminu Kano Teaching Hospital, Kano, Nigeria \\ ${ }^{2}$ Department of Obstetrics and Gynecology, Murtala Mohammed Specialist Hospital, Kano, Nigeria \\ ${ }^{3}$ Department of Pathology, Aminu Kano Teaching Hospital, Kano, Nigeria
}

Received: 11 November 2016

Accepted: 03 December 2016

\section{*Correspondence:}

Dr. Akinfenwa T. Atanda,

E-mail: atatanda.pat@buk.edu.ng

Copyright: $\odot$ the author(s), publisher and licensee Medip Academy. This is an open-access article distributed under the terms of the Creative Commons Attribution Non-Commercial License, which permits unrestricted non-commercial use, distribution, and reproduction in any medium, provided the original work is properly cited.

\begin{abstract}
Mullerian adenosarcomas are rare tumours that may be found in any part of the female genital tract including cervix. They are more common in the reproductive age group and rare among blacks. When they present in the cervix they may be clinically misdiagnosed as an endocervical polyp and histologically as an adenofibroma. Clinical presentation is mostly as irregular vagina bleeding and as a mass in the vagina. Meticulous histopathological evaluation is crucial for its optimum management.
\end{abstract}

Keywords: Adenosarcoma, Cervix, Mullerian, Polyp

\section{INTRODUCTION}

Mullerian adenosarcoma is a rare neoplasm characterized by mixed benign epithelial elements and malignant stromal components. These tumours may affect any age group including children. ${ }^{1-20}$ Mullerian adenosarcomas (MA) account for about $8 \%$ of all uterine sarcomas. ${ }^{6}$ In Nigeria, even though Omoniyi-Esan et $\mathrm{al}^{21}$ have reported 2 cases of pure sarcomas over a ten year period, our report, from available literature, is the first for MA in the country. While most commonly seen in the corpus uteri they may also be seen in other parts of the female genital tract including peritoneum. ${ }^{22}$ The mode of presentation is as a cervical polyp and is most frequently misdiagnosed as a benign endocervical polyp.

\section{CASE REPORT}

An 18-year old unmarried nulliparous woman presented to the gynaecology clinic of Murtala Mohammed Specialist Hospital, Kano, northwestern Nigeria with 3month history of a painless mass protruding through her vagina. She had also noticed cyclical abdominal pain and abnormal vagina bleeding. On examination, all her vital signs were within normal limits. A $9 \mathrm{~cm}$ mass was found protruding through the vagina to the exterior and showed no recto-abdominal involvement. A diagnosis of endocervical poly was made and excision was planned. At surgery, a huge polypoid mass originating from the endocervix and not fixed to contiguous structures was found and excised with its stalk.

The surgical specimen (Figure 1) was a firm polypoid mass with tan to haemorrhagic external surfaces measuring $9 \times 8 \times 6 \mathrm{~cm}$. Cut surfaces were predominantly solid and had multiple cystic areas some containing serosanguinous fluid.

Histologically, the mass was devoid of epithelial lining because of extensive ulceration. The lesion exhibited epithelial and sarcomatous elements. These were composed of variable-sized benign-appearing glands that were surrounded by condensed nests of mitotically active focally atypical spindle cells with foci of heterologous cartilaginous differentiation (Figure 2).

Smooth muscle invasion was also noted but this did not extend to the stalk. The spindle cells were positive for desmin while the glandular component was positive for estrogen receptor. 


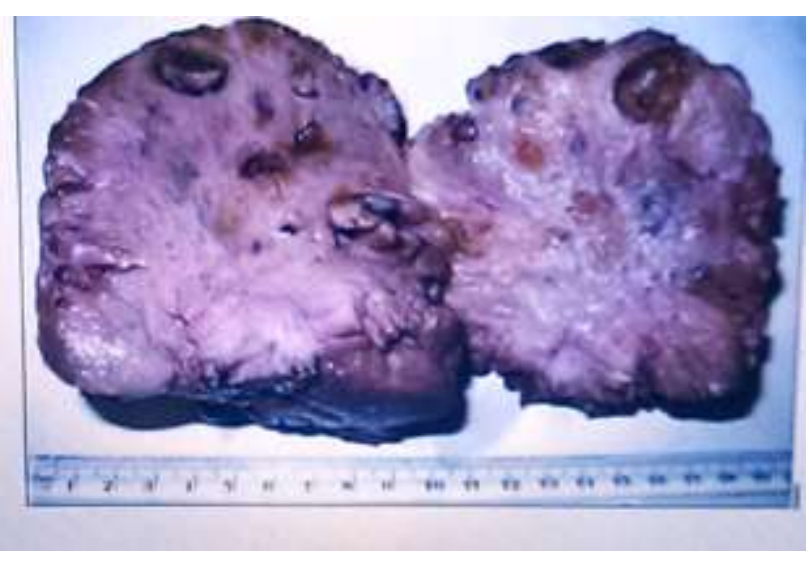

Figure 1: Gross morphology of the cervical mass showing predominantly solid fleshy surfaces.

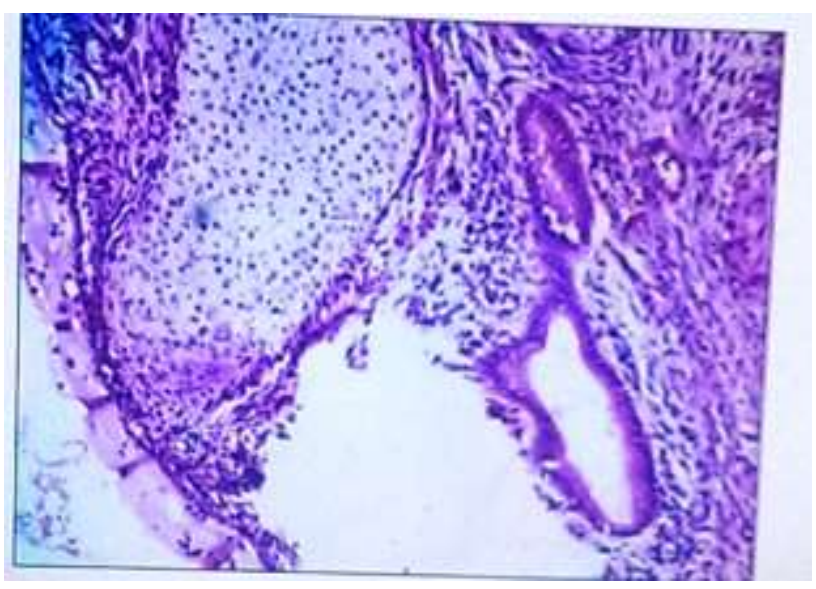

Figure 2: Microscopic appearance showing periglandular stromal condensation and heterologous cartilaginous differentiation ( $\mathrm{H}$ and $\mathrm{E} \times 200$ ).

\section{DISCUSSION}

Mullerian adenosarcomas of the cervix are rare tumours. Cervical location accounts for about $2-9 \%$ of all sites including uterus, ovary, vagina and peritoneum. ${ }^{23}$ The ages in which cervical MA occur have shown a wide variation, with the youngest reported case being in an 10 year old girl and oldest being 72 years of age. ${ }^{6}{ }^{24}$ Mean age of cases reported worldwide has been $33 \pm 18$ years. ${ }^{1-}$ 20,24

Extensive literature review shows that the most common modes of clinical presentation are irregular menstrual bleeding (41\%), painless mass in the introitus (41\%), postmenstrual bleeding $(7 \%)$, urinary retention $(7 \%)$ and postcoital bleeding and vagina discharge (3\% each). ${ }^{1-20,24}$ Our patient presented with feeling of a mass in the introitus and irregular bleeding per vaginam.

Grossly, cervical MAs have all been shown to be polypoid in shape and have measured between $2 \mathrm{~cm}$ and $18 \mathrm{~cm}$, with mean maximum diameter of approximately $8 \pm 4 \mathrm{~cm} \cdot{ }^{1-20}$ The polypoid nature of this tumour, coupled with its mode of clinical presentation as well as epidemiologic considerations may inform the tendency to clinically diagnose this lesion as the more common endocervical polyp. Thus when a polypoid cervical growth is seen in pre- or peri-menarchial girls, MA should be clinically considered.

Correct histological diagnosis and characterization of MA appear to be the cornerstone of management. The occurrence of heterologous differentiation, as seen in our case, has been about $69 \%$ and mostly as cartilage, bone and skeletal muscle. ${ }^{1-20}$ Such heterologous elements, usually cartilaginous, as seen in this case, may also be seen in adenofibroma, carcinosarcoma and embryonal rhabdomyosarcoma (ERMS). Like ERMS MAs may show cambium-like disposition but phyllodes-like histology seen in MA is not present in ERMS. The differential diagnosis from adenofibroma is also very important. In this respect the criterion employed by Zaloudek and Norris ${ }^{9}$ that when mitotic figures are $>4$ per 100 high-power fields (hpf) is a pointer to adenosarcoma becomes very useful. This case being reported exhibited 5 mitotic figures per $10 \mathrm{hpf}$. The range described in the literature has ranged between 4 and 24 per 10 hpf with a mean of $10 \pm 7$ per 10 hpf. $^{1-20}$ Adenofibromas do not also demonstrate the peri-epithelial stromal condensation seen in MA. In carcinosarcomas the epithelial component is also malignant unlike that seen in MA.

The role of histopathological diagnosis also encompasses identification of prognostic factors that are important in the management of these cases. These include smooth muscle invasion, extra-uterine spread and stromal overgrowth. All of these were not seen in our case. On the other hand, she had histological evidence of heterologous differentiation and necrosis both of which are other poor prognostic features. These poor prognostic factors have been associated with poor outcome and recurrence. $^{23}$

In terms of management options, reports have differed with regards to treatment; as not only are there no established protocols, there is also no schema for staging the lesion. Treatments given have included hysterectomy, with or without bilateral salpingo-oophorectomy, with or without pelvic lymph node clearance and with or without adjuvant chemo- and/ or radiotherapy. ${ }^{1-20}$ However, the underlying principle of management is to prevent recurrence and/or metastasis. In staging the disease it is our opinion that there may be need to carry out endometrial curettage, vaginal biopsy as well as exploratory laparotomy to exclude spread to other tissues because of their anatomical contiguity. Based on absence of negative prognostic factors and need to preserve fertility in a setting such as ours, patients may be managed conservatively by simple excision if the stalk does not show invasion. Zaloudek and Norris ${ }^{9}$ reported adoption of this modality of management in a 15 year old girl, and who was still alive at 4 years follow-up. Another patient treated this way was lost to follow up. ${ }^{17}$ Most gynaecologists however, have offered total abdominal hysterectomy and bilateral salpingo-oophorectomy 
with/without pelvic node clearance to their patients and have achieved a $69 \%$ disease free survival for follow-up periods ranging between 3 months and 13 years. ${ }^{1-8,11-16,18-}$ ${ }^{20}$ Recurrence rate has been about $10 \%$ of cases and these have also presented with pelvic metastasis.

In conclusion, this case report in an 18 year old African female shows that adenosarcomas are rarer among blacks and supports a number of other reports that have found these tumours in young premenopausal females. It also highlights the need for correct diagnosis of the tumor, particularly by the pathologist, and the management difficulties posed for the gynaecologist in managing these rare cases.

\section{Funding: No funding sources \\ Conflict of interest: None declared \\ Ethical approval: Not required}

\section{REFERENCES}

1. Charfi S, Kallel R, Mnif H, Ellouze S, Dhouib M, Guermazi M, et al. Mullerian adenosarcoma of the cervix with sarcomatous overgrowth and heterologous elements presenting as a recurrent cervical polyp. Case Rep Obstet Gynecol. 2012;2012:358302.

2. Park HM, Park MH, Kim YJ, Chun SH, Ahn JJ, Kim $\mathrm{CI}$, et al. Mullerian adenosarcoma with sarcomatous overgrowth of the cervix presenting as cervical polyp: a case report and review of the literature. Int J Gynecol Cancer. 2004;14:1024-9.

3. Comunoglu N, Comunoglu C, Bassullu N, Somunkiran A, Calay Z. Mullerian adenosarcoma with sarcomatous overgrowth of the cervix: unusual large polypoid mass. Ups J Med Sci. 2007;112:67-72.

4. Duggal R, Nijhawan R, Aggarwal N, Sikka P. Mullerian adenosarcoma (heterologous) of the cervix with sarcomatous overgrowth: a case report with review of literature. J Gynecol Oncol. 2010;21:125-8.

5. Manoharan M, Azmi MA, Soosay G, Mould T, Weekes AR. Mullerian adenosarcoma of uterine cervix: report of three cases and review of literature. Gynecol Oncol. 2007; 105:256-60.

6. Patrelli TS, Gizzo S, Di Gangi S, Guidi G, Rondinelli M, Nardelli GB. Cervical Mullerian adenosarcoma with heterologous sarcomatous overgrowth: a fourth case and review of literature. BMC cancer. 2011;11:236.

7. Roth LM, Pride GL, Sharma HM. Mullerian adenosarcoma of the uterine cervix with heterologous elements: a light and electron microscopic study. Cancer. 1976;37:1725-36.

8. Martinelli G, Pileri S, Bazzocchi F, Serra L. Mullerian adenosarcoma of the uterus: a report of 5 cases. Tumori. 1980;66:499-506.

9. Zaloudek CJ, Norris HJ. Adenofibroma and adenosarcoma of the uterus: a clinicopathologic study of 35 cases. Cancer. 1981;48:354-66.
10. Chen KT. Rhabdomyosarcomatous uterine adenosarcoma. Int J Gynecol Pathol. 1985;4:146-52.

11. Gal D, Kerner H, Beck D, Peretz BA, Eyal A, Paldi E. Mullerian adenosarcoma of the uterine cervix. Gynecol Oncol. 1988;31:445-53.

12. Kerner $\mathrm{H}$, Lichtig C. Mullerian adenosarcoma presenting as cervical polyps: a report of seven cases and review of the literature. Obstet Gynecol. 1993;81:655-9.

13. Gast MJ, Radkins LV, Jacobs AJ, Gersell D. Mullerian adenosarcoma of the cervix with heterologous elements: diagnostic and therapeutic approach. Gynecol Oncol. 1989;32:381-4.

14. Zichella L, Perrone G, De Falco V, Pelle R, Eleuteri Serpieri D. Heterologous mesodermal adenosarcoma of the endocervix. Description of a clinical case. Minerva Ginecol. 1994;46:511-4.

15. Jones MW, Lefkowitz M. Adenosarcoma of the uterine cervix: a clinicopathological study of 12 cases. Int $\mathrm{J}$ Gynecol Pathol. 1995;14:223-9.

16. Feroze M, Aravindan KP, Thomas M. Mullerian adenosarcoma of the uterine cervix. Indian $\mathrm{J}$ Cancer. 1997;34:68-72.

17. Clement PB, Zubovits JT, Young RH, Scully RE. Malignant mullerian mixed tumors of the uterine cervix: a report of nine cases of a neoplasm with morphology often different from its counterpart in the corpus. Int J Gynecol Pathol. 1998;17:211-22.

18. Ramos P, Ruiz A, Carabias E, Pinero I, Garzon A, Alvarez I. Mullerian adenosarcoma of the cervix with heterologous elements: report of a case and review of the literature. Gynecol Oncol. 2002;84:161-6.

19. Bagga R, Keepanasseril A, Srinivasan R, Dey P, Gainder S, Saha SC, et al. Adenosarcoma of the uterine cervix with heterologous elements: a case report and review of literature. Arch Gynecol Obstet. 2010;281:669-75.

20. Chin PS, Chia YN, Lim YK, Yam KL. Diagnosis and management of Mullerian adenosarcoma of the uterine cervix. Int J Gynecol Obstet. 2013;121:229-32.

21. Olutoyin G Omoniyi-Esan, Olusola B Fasubaa, Kayode A Adelusola, Olusegun S Ojo. Histological Pattern of Cervical Malignancies in Southwestern Nigeria. Trop J Obstet and Gynaecol. 2004;21:118-21.

22. McCluggage WG. Mullerian Adenosarcoma of the Female Genital Tract. Advances Anatomical Pathology. 2010;17:122-9.

23. Gillardo A, Prat J. Mullerian adenosarcoma: a clinicopathologic and immunohistochemical study of 55 cases challenging the existence of adenofibroma. Am J Surg Pathol 2009;33:278-288.

24. Fleming NA, Hopkins L, de Nanassy J, Senterman M, Black AY. Mullerian adenosarcoma of the cervix in a 10-year-old girl: case report and review of the literature. 2009;22:45-51.

Cite this article as: Atanda1 AT, Agu OC, Modu AK. Mullerian adenosarcoma of the cervix: case report. Int J Reprod Contracept Obstet Gynecol 2017;6:335-7. 